\title{
International Congress of Anatomia Clinica, 24-26 June 2019, Madrid, Spain
}

\author{
Bruno Grignon ${ }^{1} \cdot$ Fabrice Duparc ${ }^{2}$
}

Received: 12 July 2019 / Accepted: 18 July 2019 / Published online: 26 July 2019

○) Springer-Verlag France SAS, part of Springer Nature 2019

Under the presidency of Professor Jose-Ramon Sañudo Tedesco, Madrid, Spain, the XVth Congress of the European Association of Clinical Anatomy (EACA), jointly with the XIth International Simposium of Clinical and Applied Anatomy (ISCAA), was at the held from June 24th to 26th, at the Complutense University of Madrid, in Madrid, Spain. The Japanese Research Society of Clinical Anatomy (JRSCA), the Mexican Anatomica Society (SMA), and the Spanish Anatomical Society (SAS) were the invited Societies of the meeting.

The traditional opening ceremony was followed by a brilliant translational opening conference given by Professor Xavier Navarro, Barcelona, Spain, entitled "Interfacing the peripheral nervous system with advanced prostheses. Anatomical and physiological contributions."

Scientific sessions were then organized in eight sessions successively devoted to the following topics: (1) techniques in anatomy: "from donation to students' evaluations", (2) head and neck, (3) thorax and heart, (4) nervous system (central and peripheral), (5) pelvis and abdomen, (6) locomotor system, (7) applied anatomy in surgical techniques, and (8) education evaluation.

Additionally, five specific themes were animated by invited lectures, respectively, dealing with: (1) clinical anatomy, (2) imaging, (3) dissection room, (4) anatomical variations, and (5) publishing in anatomy. In alphabetical order, the speakers were: K. Akita, R. De Caro, F. Duparc, R. E. Omaña, G. Feigl, B. Grignon, D. Kachlik, B. Logan,
M. Loukas, F. Paulsen, V. Macchi, B. Moriggl, E. Talarico, and Sh. Tubbs.

Besides the oral sessions, more than 200 posters contributed to encompass a huge number of relevant topics in Clinical Anatomy.

All sessions were of high scientific level and were intensively interactive. All contributions were actively discussed, giving the opportunity to all participants to update their knowledge, to share their experience as anatomists, as teachers, and/or as clinical anatomists, to meet old colleagues and find new ones, to establish or develop close contacts, to foster new collaborations and widen their network.

Coming from 50 different countries, not only from Europe, Asia, and South America, but also from Africa, Australia, and North America, 260 participants were registered, and eventually, 245 attended the meeting.

After the scientific sessions, Madrid offered the artistic, architectural, historical, and touristic charms of one of the most attractive European capital.

Madrid, geographically the highest capital of Europe, was also, undoubtedly, for 3 days, the highest mondial summit of Clinical Anatomy.

Publisher's Note Springer Nature remains neutral with regard to jurisdictional claims in published maps and institutional affiliations.
Bruno Grignon

b.grignon@chu-nancy.fr

Fabrice Duparc

fabrice.duparc@univ-rouen.fr

1 Faculté de Médecine, Université de Lorraine, Nancy, France

2 Faculté de Médecine Pharmacie, Rouen Cedex 1, France 